\title{
PENGARUH GAYA KEPEMIMPINAN TERHADAP KEPUASAN KERJA KARYAWAN PADA PT. LION MENTARI AIRLINES
}

\section{THE EFFECT OF LEADERSHIP STYLE ON EMPLOYEE WORK SATISFACTION IN. LION MENTARI AIRLINES}

\author{
Herman $^{1}$, Nasruji ${ }^{2}$ \\ Program Studi Magister Manajemen Program Pascasarjana Universitas Riau Kepulauan ${ }^{1}$ \\ FKIP Universitas Riau Kepulauan ${ }^{2}$ \\ hermanlawyer@yahoo.co.id
}

\begin{abstract}
Abstrak
Kepemimpinan dapat dikatakan sebagai cara dari seorang pemimpin, dalam mengarahkan, mendorong, dan mengatur semua unsur-unsur didalam suatu organisasi untuk mewujudkan suatu tujuan yang akan dicapai, sehingga menghasilkan kinerja pegawai yang maksimal. Untuk meraih tujuan tersebut harus di upayakan bagaimana cara seorang pemimpin dapat memberikan dorongan semangat kerja kepada karyawan, agar sasaran maupun tujuan yang di rencanakan secara bersama dapat mencapai target. Selain itu, pemimpin dapat memberikan promosi jabatan bagi karyawan yang berprestasi agar, terciptanya kepuasan kerja karyawan. Dengan memberikan kompensasi, karyawan akan memiliki kepuasan kerja maupun semangat kerja yang tinggi untuk mencapai suatu target. Kepuasan kerja adalah keadaan emosional karyawan di mana terjadi atau pun tidak terjadi titik temu antara nilai balas jasa kerja karyawan dari perusahaan/organisasi dengan tingkat nilai balas jasa yang memang diinginkan oleh karyawan yang bersangkutan. Penelitian dilakukan pada PT. Lion Mentari Airlines. Dalam melakukan penelitian penulis menggunakan metode analisa regresi berganda dan menggunakan koefisien determinasi uji $F$ dan uji $T$ untuk melakukan pengujian hipotesis. Data yang dikumpulkan melalui kuesioner yang dibagikan kepada 50 responden karyawan PT. Lion Mentari Airlines. Dari ketiga variabel independen yang diuji secara individual, tipe kepemimpinan yang paling dominan dalam mempengaruhi kepuasan kerja karyawan adalah tipe pemimpin Otoriter $\left(X_{2}\right)$.
\end{abstract}

\section{Kata kunci : Gaya Kepemimpinan, Kepuasan Kerja, Perseroan Terbatas}

\begin{abstract}
Leadership can be said as a way of a leader, in directing, encouraging, and managing all the elements in an organization to realize a goal to be achieved, resulting in maximum employee performance. To achieve these goals must be sought on how a leader can provide encouragement to work morale to employees, so that the goals and objectives planned together can achieve the target. In addition, leaders can provide promotion for employees who have high achievements, creating job satisfaction for employees. By providing compensation, employees will have high job satisfaction and work morale to achieve a target. Job satisfaction is the emotional state of the employee where there is no meeting point between the value of the employee's work return from the company / organization and the level of remuneration that is desired by the employee. The research was conducted at PT. Lion Mentari Airlines. In conducting research the author uses multiple regression analysis methods and uses the coefficient of determination F test and T test to test hypotheses. Data collected through questionnaires distributed to 50 respondents of employees of PT. Lion Mentari Airlines. Of the three independent variables tested individually, the most dominant type of leadership in influencing employee satisfaction is the authoritarian leader type (X2).
\end{abstract}

Keywords: Leadership Style, Job Satisfaction, Limited Liability Company

\section{PENDAHULUAN}

Kepemimpinan dapat dikatakan sebagai cara dari seorang pemimpin dalam mengarahkan, mendorong, dan mengatur semua unsur-unsur didalam suatu organisasi untuk mewujudkan suatu tujuan yang akan dicapai, sehingga menghasilkan kinerja pegawai yang 
maksimal. Dengan meningkatnya kinerja pegawai berarti tercapainya hasil kerja seseorang atau pegawai dalam mencapai tujuan organisasi.

Untuk meraih tujuan tersebut harus di upayakan bagaimana cara seorang pemimpin dapat memberikan dorongan semangat kerja kepada karyawan, agar sasaran maupun tujuan yang di rencanakan secara bersama dapat mencapai target. Selain itu, pemimpin dapat memberikan promosi jabatan bagi karyawan yang berprestasi agar, terciptanya kepuasan kerja karyawan.

Selain memberikan promosi jabatan, seorang pemimipin harus memikirkan kesenangan terhadap karyawannya dengan memberikan gaji/upah yang sesuai, kemudian memberikan tunjangan setiap tahun, dan memberikan cuti. Dengan memberikan kompensasi tersebut karyawan akan memiliki kepuasan kerja maupun semangat kerja yang tinggi untuk mencapai suatu target.

Dengan demikian, untuk menjadi pemimpin (leader) harus memiliki ambisi, tanggung jawab, mempunyai semangat yang tinggi untuk memberikan motivasi terhadap karyawan, kecerdasan, kedewasaan, keluasan hubungan sosial, dan berani dalam mengambil keputusan. Agar yang direncanakan oleh perusahaan tersebut dapat terealisasikan.

\section{Landasan Teori}

Menurut Hasibuan (2012) "manajemen sumber daya manusia adalah ilmu dan seni mengatur hubungan dan peranan tenaga kerja agar efektif dan efisien membantu terwujudnya tujuan perusahaan, karyawan dan masyarakat". Menurut Dessler (2014) "manajemen sumber daya manusia adlah proses memperoleh, melatih, menilai, dan memberikan kompenisasi kepada karyawan, memperhatikan hubungan kerja mereka, kesehatan dan keamanan, serta masalah keadilan".

\section{Pengertian Kepemimpinan}

a. Kepemimpinan telah didefinisikan dengan berbagai cara yang berbeda oleh berbagai orang yang berbeda. (Handoko, 2010)

b. Kepemimpinan adalah cara atau gaya seorang pemimpin mempengaruhi perilaku bawahan, agar mau bekerja sama dan bekerja secara produktif untuk mencapai tujuan organisasi. (Hasibuan, 2010)

c. Kepemimpinan adalah aktifitas mempengaruhi perilaku orang lain baik secara individu maupun kelompok agar melakukan aktivitas dalam usaha mencapai tujuan dalam situasi tertentu. 
(Silalahi, 2012)

d. Kepemimpinan adalah keseluruhan aktifitas atau tindakan untuk mempengaruhi serta menggiatkan orang-orang dalam usaha bersama untuk mencapai tujuan. (Terry, 2016)

e. Kepemimpinan adalah seni kemampuan mempengaruhi perilaku manusia dan kemampuan untuk mengendalikan orang-orang dalam organisasi agar perilaku mereka sesuai dengan perilaku yang diinginkan oleh pimpinan, (Herujito, 2014).

\section{Tipe-tipe Kepemimpinan}

a. Tipe pemimpin pribadi, pemimpin yang tergolong tipe ini mempunyai hubungan langsung dengan para pegawainya. Kepemimpinan semacam ini biasanya sangat efektif didalam usaha apa pun baik kecil maupun besar.

b. Tipe pemimpin non-pribadi, tipe pemimpin semacam ini hubungannya dengan para pegawainya sama sekali kurang atau berjalan tidak langsung, karena kepemimpinan yang dilakukan melalui cara-cara yang personal seperti perintah-perintah tertulis, keputusan-keputusan, pengamanan-pengamanan yang mengandung adanya bimbingan, rencana panji dan sumpah.

c. Tipe pemimpin otoriter, suatu bentuk kepemimpinan yang mempunyai karakteristik negatif dan sangat egois terhadap para bawahan.

d. Tipe pemimpin demokratis, dalam tipe kepemimpinan demokratis golongan pelaksana berpartisipasi penuh dalam mencapai tujuan organisasi tanpa ada rasa paksaan, disamping itu turut mengembangkan pemikiran-pemikiran dalam menentukan dan atau memutuskan metode-metode yang terbaik dalam pelaksanaan pekerjaan atau dengan pengertian lain.

e. Tipe kepemimpinan paternalitas (kebapaan), suatu tipe pemimpin yang bersifat seperti bapak yaitu sebagai pendidik, pengasuh, pembimbing, penasihat, tukang memerintah dan kurang mau menerima pendapat pengikutnya.

f. Tipe pemimpin alamiah, tipe kepemimpinan yang terbentuk tanpa ada yang mengangkat atau dengan kata lain kepemimpinan yang terjadi secara spontan yaitu atas dukungan dari para pengikut-pengikutnya.

g. Tipe pemimpin militeristis, model kepemimpinan yang kaku karena dalam mengarahkan pengikut-pengikutnya selalu bergantung pada pangkat dan 
jabatannya, senang kepada formalitas yang berlebihan dan tidak mau dikritik, menggemari atau menyukai upacara-upacara dan penghormatan yang berlebihan.

h. Tipe kepemimpinan kharismatis, mempunyai daya tarik yang amat besar terhadap pengikut-pengikutnya, seakan-akan dalam diri pemimpin tersebut terdapat suatu kekuatan yang luar biasa sehingga dalam waktu singkat banyak pengikutnya, dan pengikutnya tersebut tidak mengerti mengapa mereka terbius untuk mengikutnya.

i. Tipe pemimpin yang terbuka, tipe kepemimpinan ini corak hampir sama dengan tipe kepemimpinan demokratis, namun perbedaanya terletak dalam pengambilan keputusan, dimana dalam hal ini keputusan berada ditangan pemimpin.

j. Tipe pemimpin konservatif, dalam kepemimpinan ini diharapkan seorang pemimpin dapat memperjuangkan hal-hal yang sudah lewat dan dapat pula memperjuangkan hal-hal baru dan perubahan sosial.

k. Tipe pemimpin partisan, suatu corak kepemimpinan yang memihak, selalu pro dan kontra terhadap sesuatu. Pertimbangan dalam memihak demi kepentingan kelompoknya.

1. Tipe pemimpin yang bertahan dan serba terima, suatu tipe kepemimpinan yang mempunyai kepercayaan penuh terhadap pembantu-pembantu atau penasihatpenasihatnya. Dia lebih suka menerima yang dianggap baik dari orang kepercayaannya.

m. Tipe pemimpin yang serba menimbun, corak kepemimpinan sejenis ini sifatnya tertutup, kurang menerima hal-hal baru dan menganggap dirinya selalu yang benar, tidak menginginkan adanya kaderasi takut "dilangkahi” atau digeser.

n. Tipe pemimpin menyerang atau mengisap, corak kepemimpinan jenis berpedoman terhadap perasaannya bahwa sumber segala kebaikan berada dari luar yaitu dengan merebut dari orang lain dengan jalan kekerasan bila perlu dengan cara tipu msulihat.

o. Tipe pemimpin marketing, suatu corak kepemimpinan yang selalu berorientasi ke masa depan organisasi yaitu dengan selalu meningkatkan kemampuan atau dengan kata lain memperlakukan dirinya sebagai barang dagangan.

p. Tipe pemimpin produktif, suatu tipe pemimpin yang produktif dimana segala kecerdasan, kecakapan, dan kekuatannya diberikan kepada organisasi yang dipimpinnya hingga menjadi kenyataan. 


\section{Pengertian Kepuasan Kerja Karyawan}

1. Kepuasan kerja (job statisfaction) merupakan seperangkat perasaan pegawai tentang menyenangkan atau tidak menyenangkan pekerjaan mereka. (Davis, 2012)

2. Kepuasan kerja menyatakan bahwa "kepuasan kerja sebagai suatu sikap umum seorang individu terhadap pekerjaannya”. (Robbins, 2011).

3. Kepuasan kerja adalah penilaian atau cerminan dari perasaan pekerja terhadap kerjaannya dan akan tampak dalam sikap positif pekerja atas segala sesuatu yang dihadapi lingkungan kerjanya dan terhadap pekerjaannya. (Setiawan, 2012).

\section{METODOLOGI}

\section{Identifikasi Variabel}

a. Adapun yang merupakan variabel bebas $(\mathrm{X})$ adalah gaya kepemimpinan dengan sub-sub variabel:

$\left(\mathrm{X}_{1}\right)$ Tipe pemimpin paternalitas

$\left(\mathrm{X}_{2}\right)$ Tipe pemimpin otoriter

$\left(\mathrm{X}_{3}\right)$ Tipe pemimpin partisan

b. Variabel terikat (dependent) yaitu merupakan variabel yang dipengaruhi oleh variabel bebas. Adapun variabel terikat dalam penelitian ini adalah: Kepuasan kerja karyawan (Y).

\section{Definisi Konseptual Variabel}

Variabel bebas (X), yaitu: Gaya kepemimpinan

Sedangkan sub variabel gaya kepemimpinan dalam penelitian ini terdiri dari:

1. Tipe kepemimpinan paternalitas (kebapaan) $\left(X_{1}\right)$, suatu tipe pemimpin yang bersifat seperti bapak yaitu sebagai pendidik, pengasuh, pembimbing, penasihat, tukang memerintah dan kurang mau menerima pendapat pengikutnya.

2. Tipe pemimpin otoriter $\left(X_{2}\right)$, suatu bentuk kepemimpinan yang mempunyai karakteristik negatif dan sangat egois terhadap para bawahan.

3. Tipe pemimpin partisan $\left(X_{3}\right)$, suatu corak kepemimpinan yang memihak, selalu pro dan kontra terhadap sesuatu. Pertimbangan dalam memihak demi kepentingan kelompoknya.

Variabel terikat (Y) yaitu: Kepuasan kerja 


\section{Definisi Operasional Variabel}

1. Gaya kepemimpinan (X)

2. Tipe kepemimpinan paternalitas (kebapaan) $\left(\mathrm{X}_{1}\right)$

3. Tipe pemimpin otoriter $\left(\mathrm{X}_{2}\right)$

4. Tipe pemimpin partisan $\left(\mathrm{X}_{3}\right)$

5. Kepuasan kerja (job statisfaction) $(\mathrm{Y})$

\section{Populasi dan Sampel}

\section{Populasi}

Populasi adalah keseluruhan subyek penelitian, sedangkan sampel adalah wakil populasi yang diteliti. Populasinya adalah staf dan karyawan pada bagian call center berjumlah 402 orang.

\section{Sampel dan Teknik Penarikan Sampel}

Mengingat keterbatasan waktu, tenaga serta biaya yang besar, maka pengambilan sampel yang dilakukan terhadap sebagian dari jumlah populasi yang ada, yaitu sebesar 50 karyawan. Adapun teknik penarikan sampel yang digunakan adalah menggunakan simple random sampling adalah "Pengambilan sampel secara acak dimana anggota sampelnya mendapatkan kesempatan yang sama untuk dijadikan sampel", Iqbal (2012).

\section{Uji Validitas dan Reliabilitas Instrumen}

\section{Uji Validitas}

Uji validitas ini diperoleh dengan cara mengkorelasi setiap skor item dengan total skor item variabel, kemudian hasil korelasi dibandingkan dengan nilai kritis pada taraf siginifikan 0,05. Suatu instrumen dikatakan valid apabila mampu mengukur apa yang diinginkan dan tinggi rendahnya validitas instrumen menunjukkan sejauh mana data yang terkumpul tidak menyimpang dari gambaran tentang variabel yang dimaksud.

Di dalam melakukan pengujian validitas menurut Arikunto (1997:162), menggunakan rumus sebagai berikut:

$$
r_{x y}=\frac{n\left(\sum X Y\right)-\left(\sum X\right)\left(\sum Y\right)}{\sqrt{\left[n\left(\sum X^{2}\right)-\left(\sum X\right)^{2} n\left(\sum Y^{2}\right)-\left(\sum Y\right)^{2}\right]}}
$$

Dimana:

$r=$ Koefisien korelasi 
$\mathrm{n}$ = Banyaknya sampel

$\mathrm{x}=$ Variabel yang mempengaruhi

$\mathrm{y}=$ Variabel yang dipengaruhi

\section{Uji Reliabilitas}

Uji reliabilitas ini dilakukan dengan cara mengkorelasikan antara satu score item dalam setiap variabel, kemudian dari hasil korelasi dibandingkan dengan nilai kritis (critical value) pada taraf signifikan 0,05. Jika koefisien korelasi lebih besar dari nilai kritis, maka pengukuran tersebut dikatakan reliabel dan sebaliknya jika nilai koefisien korelasi lebih kecil dari nilai kritis (critical value), maka pengukuran tersebut tidak reliabel atau tidak dapat diandalkan.

$$
r_{x y}=\frac{n \sum X Y-\sum X \sum Y}{\sqrt{\left[n \sum X^{2}-\left(\sum X\right)^{2} \mid n \sum Y^{2}-\left(\sum Y\right)^{2}\right]}}
$$

Dimana:

$r=$ Koefisien korelasi

$\mathrm{n}=$ Banyaknya sampel

$\mathrm{x}=$ Variabel yang mempengaruhi

$\mathrm{y}=$ Variabel yang dipengaruhi

\section{Teknik Analisis Data}

Setelah data terkumpul, maka langkah selanjutnya adalah melakukan analisis terhadap data agar berarti dan dapat diintepretasikan. Sesuai dengan tujuan penelitian yaitu untuk mengetahui hubungan dan pengaruh variabel bebas terhadap variabel terikat, maka analisis data yang dilakukan bertujuan untuk mengkaji kebenaran hipotesis bersama penjelasannya.

\section{Analisis regresi berganda}

Berdasarkan permasalahan dan hipotesis yang telah disajikan, maka teknik analisa yang digunakan dalam penelitian ini adalah sebagai berikut:

$\mathbf{y}=\mathbf{a}+\mathbf{b}_{1} \mathbf{x}_{1}+\mathbf{b}_{2} \mathbf{x}_{2}+\mathbf{b}_{3} \mathbf{x}_{3}+\mathbf{e}$

Dimana :

$$
\begin{array}{ll}
\mathrm{Y} & =\text { Variabel terikat } \\
\mathrm{a} & =\text { Konstata } \\
\mathrm{b}_{1} \ldots \mathrm{b}_{3} & =\text { Koefisien regresi } \mathrm{X}_{1} \ldots . . \mathrm{X}_{3} \\
\mathrm{X}_{1} & =\text { Tipe pemimpin paternalitas } \\
\mathrm{X}_{2} & =\text { Tipe pemimpin otoriter }
\end{array}
$$


$\mathrm{X}_{3} \quad=$ Tipe pemimpin partisan

$\mathrm{Y} \quad=$ kepuasan kerja karyawan

Dari hasil pengolahan data dengan program SPSS For Windows versi 19.0 akan dilakukan analisis secara diskriptif dan pembuktian hipotesis.

\section{Uji Hipotesis (Uji F dan Uji t)}

H0 : Adanya pengaruh gaya kepemimpinan terhadap kepuasan kerja karyawan.

Ha : Tidak adanya pengaruh gaya kepemimpinan terhadap kepuasan kerja karyawan.

\section{a) Uji serempak (Uji F)}

Untuk menguji kebenaran hipotesis pertama digunakan uji $\mathrm{F}$ yaitu untuk menguji keberartian regresi secara keseluruhan dengan rumus hipotesis sebagai berikut :

$\mathrm{H} 0: \mathrm{b} 1=\mathrm{b} 2=\mathrm{b} 3=0$

Ha : bi = minimal satu koefisien $\square \square 0$

Pengujian dengan uji $\mathrm{F}$ variansnya adalah dengan membandingkan Fhitung (Fh) dengan Ftabel (Ft) pada $\square \square=0,05$ apabila hasil perhitungannya menunjukkan :

1) $\mathrm{Fh} \geq \mathrm{Ft}$, maka $\mathrm{H} 0$ ditolak dan $\mathrm{Ha}$ diterima

Artinya variasi dari model regresi berhasil menerangkan variasi variabel bebas secara keselururan, sejauh mana pengaruhnya terhadap variabel tidak bebas (variabel terikat).

2) $\mathrm{Fh}<\mathrm{Ft}$, maka H0 diterima dan Ha ditolak

Artinya variasi dari model regresi tidak berhasil menerangkan variasi variabel bebas secara keseluruhan, sejauh mana pengaruhnya terhadap variabel tidak bebas (variabel terikat).

\section{b) Uji Parsial (Uji t)}

Untuk menguji kebenaran hipotesis kedua langkah pertama yang dilakukan adalah menentukan koefisien regresi (bi) yang paling besar, selanjutnya dilakukan pengujian secara parsial melalui uji t. adapun rumusan hipotesis dengan menggunakan uji t adalah sebagai berikut :

$\mathrm{H} 0: \mathrm{b} 1=\mathrm{b} 2=\mathrm{b} 3=0$

Ha : bi $\square \square 0$ 
Pengujian dilakukan melalui uji t dengan membandingkan dengan $\mathrm{t}$ tabel (tt) pada $\square \square 0,05$. Apabila hasil perhitungan menunjukkan :

1) th $\geq$ tt maka HO ditolak dan Ha diterima

Artinya variasi variabel bebas dapat menerangkan variabel tidak bebas (variabel terikat) dan terdapat pengaruh diantara kedua variabel yang diuji.

2) th $<$ tt maka H0 diterima dan Ha ditolak

Artinya variasi bebas tidak dapat menerangkan variabel tidak bebas (variabel terikat) dan terdapat pengaruh antara dua variabel ynang diuji.

Untuk membuktikan hipotesis pertama, yaitu untuk mengetahui besarnya pengaruh secara keseluruhan dihitung koefisien determinasi multiplenya (R2). Jika R2 yang diperoleh dari hasil perhitungan mendekati 1 (satu), maka semakin kuat model tersebut dapat menerangkan variabel tergantungnya. Kemudian dilakukan pengujian variansnya dengan uji $\mathrm{f}$.

Hipotesi diterima apabila titik lebih besar dari t tabel $(\mathrm{fh}>\mathrm{ft}$ ) atau diperoleh harga $\mathrm{p}<0,05$. Untuk membuktikan hipotesis kedua, masing-masing koefisien regresinya diuji dengan uji t. Hasil uji t bermakna apabila diperoleh thitung lebih besar dari ttabel (th $>\mathrm{tt}$ ) atau diperoleh harga $\mathrm{p}<0,05$. Untuk pengaruh yang dominan ditentukan oleh harga p yang terkecil atau R2 parsial yang terbesar.

\section{PEMBAHASAN}

\section{Profil PT. Lion Mentari Airlines}

PT. Lion Mentari Airlines, beroperasi (wisata dan maskapai) sebagai Lion Air adalah maskapai penerbangan swasta terbesar di Indonesia. Didirikan pada tannggal 19 Oktober 1999 dengan Pemilik Rusdi Kirana. Berkantor pusat di Jakarta, Indonesia. Maskapai beroperasi pada tanggal 30 juni 2000, dimana maskapai penerbangan ini menguasai sebagian besar pangsa pasar domestik. Lion Air terbang ke kota-kota di Indonesia, Singapura,

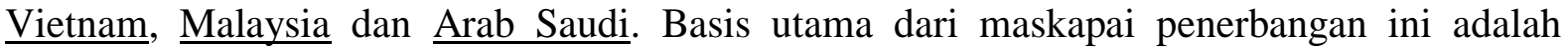
Bandar Udara Internasional Soekarno-Hatta, Jakarta. Maskapai ini mengoperasikan penerbangan penumpang berjadwal dengan jaringan yang luas dari Jakarta ke 56 tujuan (per Juli 2010). Mempunyai anak perusahaan wings air, lion bizjet, batik air, malindo airways. Perusahaan ini memiliki slogan "We Make People Fly”. 


\section{Karakteristik responden}

Sebelum mengolah data kuisioner, penulis terlebih dahulu mengidentifikasi karakteristik dari masing-masing responden yang terdiri dari : tingkat pendidikan, tingkat usia, tingkat lama bekerja, dan tingkat jenis kelamin.

1. Tingkat pendidikan, Dalam mengidentifikasi tingkat pendidikan, penulis membagi tingkat pendidikan menjadi 4 tingkat, yaitu : SMA, SMK, Diploma 3 dan Sarjana.

2. Tingkat usia, Dalam mengidentifikasi tingkat usia, penulis membagi tingkat usia menjadi 2 kriteria yaitu, 18 sampai 20 tahun, dan 20 sampai 25 tahun.

3. Tingkat lama bekerja, Dalam mengidentifikasi tingkat lama bekerja, penulis membagi tingkat lama bekerja menjadi 2 kriteria yaitu, kurang dari 1 tahun dan lebih dari 1 tahun.

4. Tingkat Jenis kelamin, Dalam mengidentifikasi tingkat jenis kelamin, penulis membagi tingkat jenis kelamin menjadi 2 kriteria yaitu, laki-laki dan perempuan.

\section{Perhitungan Skala Likert}

Skala likert adalah suatu skala psikometrik yang umum digunakan dalam kuisioner, dan merupakan skala yang banyak digunakan dalam riset berupa survei. Nama skala ini diambil dari nama Rensis Likert, yang menerbitkan suatu laporan yang menjelaskan penggunaannya. Sewaktu menanggapi pertanyaan dalam skala likert, responden menentukan tingkat persetujuan mereka terhadap suatu pernyataan dengan memilih salah satu dari pilihan yang tersedia. Biasanya disediakan lima pilihan skala dengan format berikut ini :

$\begin{array}{ll}\text { Sangat Setuju (SS) diberi nilai } & =5 \\ \text { Setuju (S) diberi nilai } & =4 \\ \text { Netral (N) diberi nilai } & =3 \\ \text { Tidak Setuju (TS) diberi nilai } & =2 \\ \text { Sangat Tidak Setuju (STS) diberi nilai } & =1\end{array}$

Pada pertanyaan pertama pada variabel kepemimpinan $\left(\mathrm{X}_{1}\right.$ :tipe pemimpin paternalitas) yaitu, "Atasan saya selalu membimbing setiap pekerjaan saya" didapatkan hasil sebagai berikut: 
Tabel 1

"Variabel kepemimpinan $\left(\mathrm{X}_{1}\right)$ ", pertanyaan no. 1

\begin{tabular}{|l|l|l|l|l|l|l|}
\hline Penilaian & STS & TS & N & S & SS & Jumlah \\
\hline Bobot & 1 & 2 & 3 & 4 & 5 & \\
\hline Frekuensi & 2 & 2 & 13 & 26 & 7 & 50 \\
\hline Presentase & $4 \%$ & $4 \%$ & $26 \%$ & $52 \%$ & $14 \%$ & $100 \%$ \\
\hline Nilai & 2 & 4 & 39 & 104 & 35 & \\
\hline
\end{tabular}

Sumber: Data diperoleh dari kuisioner

Pada Tabel 1 variabel kepemimpinan diatas dapat terlihat responden yang menyatakan sangat tidak setuju sebanyak (4\%), tidak setuju sebanyak (4\%), netral sebanyak (26\%), setuju sebanyak (52\%), dan sangat setuju sebanyak (14\%).

Pada pertanyaan kedua pada variabel kepemimpinan $\left(\mathrm{X}_{1}\right.$ :tipe pemimpin paternalitas) yaitu, "Atasan saya menasehati saya apabila ada kesalahan" didapatkan hasil sebagai berikut:

Tabel 2

"Variabel kepemimpinan $\left(\mathrm{X}_{1}\right)$ ", pertanyaan no. 2

\begin{tabular}{|l|l|l|l|l|l|l|}
\hline Penilaian & STS & TS & N & S & SS & Jumlah \\
\hline Bobot & 1 & 2 & 3 & 4 & 5 & \\
\hline Frekuensi & 2 & 4 & 7 & 23 & 14 & 50 \\
\hline Presentase & $4 \%$ & $8 \%$ & $14 \%$ & $46 \%$ & $28 \%$ & $100 \%$ \\
\hline Nilai & 2 & 8 & 21 & 92 & 70 & \\
\hline
\end{tabular}

Sumber: Data diperoleh dari kuisioner

Pada Tabel 2 variabel kepemimpinan diatas dapat terlihat responden yang menyatakan sangat tidak setuju sebanyak (4\%), tidak setuju sebanyak (8\%), netral sebanyak (14\%), setuju sebanyak (46\%), dan sangat setuju sebanyak (28\%).

Pada pertanyaan ketiga pada variabel kepemimpinan $\left(\mathrm{X}_{1}\right.$ :tipe pemimpin paternalitas) yaitu, "Atasan saya memberikan pembelajaran yang mendidik dengan pekerjaan saya" didapatkan hasil sebagai berikut:

Tabel 3

\begin{tabular}{|l|l|l|l|l|l|l|}
\multicolumn{8}{|c}{ "Variabel kepemimpinan $\left(\mathbf{X}_{1}\right)$ ", pertanyaan no. 3 } \\
\hline Penilaian & STS & TS & N & S & SS & Jumlah \\
\hline Bobot & 1 & 2 & 3 & 4 & 5 & \\
\hline Frekuensi & 3 & 2 & 11 & 30 & 4 & 50 \\
\hline Presentase & $6 \%$ & $4 \%$ & $22 \%$ & $60 \%$ & $8 \%$ & $100 \%$ \\
\hline Nilai & 3 & 4 & 33 & 120 & 20 & \\
\hline
\end{tabular}

Sumber: Data diperoleh dari kuisioner 
Pada Tabel 3 variabel kepemimpinan diatas dapat terlihat responden yang menyatakan sangat tidak setuju sebanyak (6\%), tidak setuju sebanyak (4\%), netral sebanyak (22\%), setuju sebanyak (60\%), dan sangat setuju sebanyak (8\%).

Pada pertanyaan keempat pada variabel kepemimpinan $\left(\mathrm{X}_{1}\right.$ :tipe pemimpin paternalitas) yaitu, "Atasan saya kurang menerima setiap saran yang saya berikan" didapatkan hasil sebagai berikut:

\section{Tabel 4}

"Variabel kepemimpinan $\left(\mathrm{X}_{1}\right)$ ", pertanyaan no. 4

\begin{tabular}{|l|l|l|l|l|l|l|}
\hline Penilaian & STS & TS & N & S & SS & Jumlah \\
\hline Bobot & 1 & 2 & 3 & 4 & 5 & \\
\hline Frekuensi & 3 & 15 & 21 & 8 & 3 & 50 \\
\hline Presentase & $6 \%$ & $30 \%$ & $42 \%$ & $16 \%$ & $6 \%$ & $100 \%$ \\
\hline Nilai & 3 & 30 & 63 & 32 & 15 & \\
\hline
\end{tabular}

Sumber: Data diperoleh dari kuisioner

Pada Tabel 4 variabel kepemimpinan diatas dapat terlihat responden yang menyatakan sangat tidak setuju sebanyak (6\%), tidak setuju sebanyak (30\%), netral sebanyak (42\%), setuju sebanyak (16\%), dan sangat setuju sebanyak (6\%).

Pada pertanyaan kelima pada variabel kepemimpinan $\left(\mathrm{X}_{1}\right.$ :tipe pemimpin paternalitas) yaitu, "Atasan saya kurang menerima setiap saran yang saya berikan" didapatkan hasil sebagai berikut:

\section{Tabel 5}

"Variabel kepemimpinan $\left(\mathrm{X}_{1}\right)$ ", pertanyaan no. 5

\begin{tabular}{|l|l|l|l|l|l|l|}
\hline Penilaian & STS & TS & N & S & SS & Jumlah \\
\hline Bobot & 1 & 2 & 3 & 4 & 5 & \\
\hline Frekuensi & 3 & 8 & 16 & 19 & 4 & 50 \\
\hline Presentase & $6 \%$ & $16 \%$ & $32 \%$ & $38 \%$ & $8 \%$ & $100 \%$ \\
\hline Nilai & 3 & 16 & 48 & 76 & 20 & \\
\hline
\end{tabular}

Sumber: Data diperoleh dari kuisioner

Pada Tabel 5 variabel kepemimpinan diatas dapat terlihat responden yang menyatakan sangat tidak setuju sebanyak (6\%), tidak setuju sebanyak (16\%), netral sebanyak (32\%), setuju sebanyak (38\%), dan sangat setuju sebanyak (8\%).

Pada pertanyaan pertama pada variabel kepemimpinan $\left(\mathrm{X}_{2}\right.$ : Tipe pemimpin otoriter) yaitu, "Atasan saya memiliki sifat yang sulit menerima pendapat orang lain" didapatkan hasil sebagai berikut: 
Tabel 6

Variabel kepemimpinan $\left(X_{2}\right)$ pertanyaan no. 1

\begin{tabular}{|l|l|l|l|l|l|l|}
\hline Penilaian & STS & TS & N & S & SS & Jumlah \\
\hline Bobot & 1 & 2 & 3 & 4 & 5 & \\
\hline Frekuensi & 1 & 15 & 21 & 10 & 3 & 50 \\
\hline Persentase & $2 \%$ & $30 \%$ & $42 \%$ & $20 \%$ & $6 \%$ & $100 \%$ \\
\hline Nilai & 1 & 30 & 63 & 40 & 15 & \\
\hline
\end{tabular}

Sumber: Data diperoleh dari kuisioner

Pada Tabel 6 variabel kepemimpinan $\left(\mathrm{X}_{2}\right.$ : tipe pemimpin otoriter $)$ diatas dapat terlihat responden yang menyatakan sangat tidak setuju sebanyak (2\%), tidak setuju sebanyak (30\%), netral sebanyak (42\%), setuju sebanyak (20\%), dan sangat setuju sebanyak $(6 \%)$.

Pada pertanyaan kedua pada variabel kepemimpinan $\left(\mathrm{X}_{2}\right.$ : Tipe pemimpin otoriter) yaitu, "Atasan saya mempunyai hak dan kekuasaan penuh dalam pekerjaan" didapatkan hasil sebagai berikut:

\section{Tabel 7}

Variabel kepemimpinan $\left(\mathrm{X}_{2}\right)$, pertanyaan no. 2

\begin{tabular}{|l|l|l|l|l|l|l|}
\hline Penilaian & STS & TS & N & S & SS & Jumlah \\
\hline Bobot & 1 & 2 & 3 & 4 & 5 & \\
\hline Frekuensi & 2 & 10 & 15 & 18 & 5 & 50 \\
\hline Persentase & $4 \%$ & $20 \%$ & $30 \%$ & $36 \%$ & $10 \%$ & $100 \%$ \\
\hline Nilai & 2 & 20 & 45 & 72 & 25 & \\
\hline
\end{tabular}

Sumber: Data diperoleh dari kuisioner

Pada Tabel 7 variabel kepemimpinan $\left(\mathrm{X}_{2}\right.$ : tipe pemimpin otoriter $)$ diatas dapat terlihat responden yang menyatakan sangat tidak setuju sebanyak (4\%), tidak setuju sebanyak (20\%), netral sebanyak (30\%), setuju sebanyak (36\%), dan sangat setuju sebanyak (10\%).

Pada pertanyaan ketiga pada variabel kepemimpinan $\left(\mathrm{X}_{2}\right.$ : Tipe pemimpin otoriter) yaitu, "Atasan saya sering memutuskan keputusan tanpa musyawarah dengan karyawan" didapatkan hasil sebagai berikut:

Tabel 8

Variabel kepemimpinan $\left(\mathrm{X}_{2}\right)$, pertanyaan no. 3

\begin{tabular}{|l|l|l|l|l|l|l|}
\hline Penilaian & STS & TS & N & S & SS & Jumlah \\
\hline Bobot & 1 & 2 & 3 & 4 & 5 & \\
\hline Frekuensi & 3 & 20 & 16 & 8 & 3 & 50 \\
\hline Persentase & $6 \%$ & $40 \%$ & $32 \%$ & $16 \%$ & $6 \%$ & $100 \%$ \\
\hline Nilai & 3 & 40 & 48 & 32 & 15 & \\
\hline
\end{tabular}

Sumber: Data diperoleh dari kuisioner 
Pada Tabel 8 variabel kepemimpinan $\left(\mathrm{X}_{2}\right.$ : tipe pemimpin otoriter $)$ diatas dapat terlihat responden yang menyatakan sangat tidak setuju sebanyak (6\%), tidak setuju sebanyak (40\%), netral sebanyak (32\%), setuju sebanyak (16\%), dan sangat setuju sebanyak (6\%).

Pada pertanyaan keempat pada variabel kepemimpinan $\left(\mathrm{X}_{2}\right.$ : Tipe pemimpin otoriter) yaitu, "Atasan saya tidak pernah mendukung kreatifitas pekerjaan" didapatkan hasil sebagai berikut:

\section{Tabel 9}

Variabel kepemimpinan $\left(X_{2}\right)$, pertanyaan no. 4

\begin{tabular}{|l|l|l|l|l|l|l|}
\hline Penilaian & STS & TS & N & S & SS & Jumlah \\
\hline Bobot & 1 & 2 & 3 & 4 & 5 & \\
\hline Frekuensi & 1 & 20 & 21 & 6 & 2 & 50 \\
\hline Persentase & $2 \%$ & $40 \%$ & $42 \%$ & $12 \%$ & $4 \%$ & $100 \%$ \\
\hline Nilai & 1 & 40 & 63 & 24 & 10 & \\
\hline
\end{tabular}

Sumber: Data diperoleh dari kuisioner

Pada Tabel 9 variabel kepemimpinan $\left(\mathrm{X}_{2}\right.$ : tipe pemimpin otoriter $)$ diatas dapat terlihat responden yang menyatakan sangat tidak setuju sebanyak (2\%), tidak setuju sebanyak (40\%), netral sebanyak (42\%), setuju sebanyak (12\%), dan sangat setuju sebanyak (4\%).

Pada pertanyaan kelima pada variabel kepemimpinan $\left(\mathrm{X}_{2}\right.$ : Tipe pemimpin otoriter) yaitu, "Atasan saya lebih mementingkan keputusannya sendiri daripada karyawan" didapatkan hasil sebagai berikut:

Tabel 10

Variabel kepemimpinan $\left(\mathbf{X}_{2}\right)$, pertanyaan no. 5

\begin{tabular}{|l|l|l|l|l|l|l|}
\hline Penilaian & STS & TS & N & S & SS & Jumlah \\
\hline Bobot & 1 & 2 & 3 & 4 & 5 & \\
\hline Frekuensi & 8 & 13 & 15 & 7 & 7 & 50 \\
\hline Persentase & $16 \%$ & $26 \%$ & $30 \%$ & $14 \%$ & $14 \%$ & $100 \%$ \\
\hline Nilai & 8 & 26 & 45 & 28 & 35 & \\
\hline
\end{tabular}

Sumber: Data diperoleh dari kuisioner

Pada Tabel 10 variabel kepemimpinan $\left(\mathrm{X}_{2}\right.$ : tipe pemimpin otoriter $)$ diatas dapat terlihat responden yang menyatakan sangat tidak setuju sebanyak (16\%), tidak setuju sebanyak (26\%), netral sebanyak (30\%), setuju sebanyak (14\%), dan sangat setuju sebanyak $(14 \%)$. 
Pada pertanyaan pertama pada variabel kepemimpinan $\left(\mathrm{X}_{3}\right.$ : Tipe pemimpin partisan) yaitu, "Atasan saya selalu pro atau kontra terhadap sesuatu keputusan" didapatkan hasil sebagai berikut:

Tabel 11

Variabel kepemimpinan $\left(\mathbf{X}_{3}\right)$, pertanyaan no. 1

\begin{tabular}{|l|l|l|l|l|l|l|}
\hline Penilaian & STS & TS & N & S & SS & Jumlah \\
\hline Bobot & 1 & 2 & 3 & 4 & 5 & \\
\hline Frekuensi & 2 & 4 & 33 & 9 & 2 & 50 \\
\hline Persentase & $4 \%$ & $8 \%$ & $66 \%$ & $18 \%$ & $4 \%$ & $100 \%$ \\
\hline Nilai & 2 & 8 & 99 & 36 & 10 & \\
\hline
\end{tabular}

Sumber: Data diperoleh dari kuisioner

Pada Tabel 11 variabel kepemimpinan $\left(\mathrm{X}_{3}\right.$ : tipe pemimpin partisan ) diatas dapat terlihat responden yang menyatakan sangat tidak setuju sebanyak (4\%), tidak setuju sebanyak (8\%), netral sebanyak (66\%), setuju sebanyak (18\%), dan sangat setuju sebanyak (4\%).

Pada pertanyaan kedua pada variabel kepemimpinan $\left(\mathrm{X}_{3}\right.$ : Tipe pemimpin partisan) yaitu, "Atasan saya selalu mementingkan kelompok kerja karyawannya" didapatkan hasil sebagai berikut:

Tabel 12

Variabel kepemimpinan $\left(X_{3}\right)$, pertanyaan no. 2

\begin{tabular}{|l|l|l|l|l|l|l|}
\hline Penilaian & STS & TS & N & S & SS & Jumlah \\
\hline Bobot & 1 & 2 & 3 & 4 & 5 & \\
\hline Frekuensi & 0 & 6 & 22 & 21 & 1 & 50 \\
\hline Persentase & $0 \%$ & $12 \%$ & $44 \%$ & $42 \%$ & $2 \%$ & $100 \%$ \\
\hline Nilai & 0 & 12 & 66 & 84 & 6 & \\
\hline
\end{tabular}

Sumber: Data diperoleh dari kuisioner

Pada Tabel 12 variabel kepemimpinan ( $\mathrm{X}_{3}$ : tipe pemimpin partisan ) diatas dapat terlihat responden yang menyatakan sangat tidak setuju sebanyak $(0 \%)$, tidak setuju sebanyak (12\%), netral sebanyak (44\%), setuju sebanyak (42\%), dan sangat setuju sebanyak $(2 \%)$.

Pada pertanyaan ketiga pada variabel kepemimpinan $\left(\mathrm{X}_{3}\right.$ : Tipe pemimpin partisan) yaitu, "Atasan saya memiliki sifat pemimpin yang memihak" didapatkan hasil sebagai berikut: 
Tabel 13

Variabel kepemimpinan $\left(X_{3}\right)$, pertanyaan no. 3

\begin{tabular}{|l|l|l|l|l|l|l|}
\hline Penilaian & STS & TS & N & S & SS & Jumlah \\
\hline Bobot & 1 & 2 & 3 & 4 & 5 & \\
\hline Frekuensi & 2 & 15 & 22 & 8 & 3 & 50 \\
\hline Persentase & $4 \%$ & $30 \%$ & $44 \%$ & $16 \%$ & $6 \%$ & $100 \%$ \\
\hline Nilai & 2 & 30 & 66 & 32 & 15 & \\
\hline
\end{tabular}

Sumber: Data diperoleh dari kuisioner

Pada Tabel 13 variabel kepemimpinan ( $\mathrm{X}_{3}$ : tipe pemimpin partisan ) diatas dapat terlihat responden yang menyatakan sangat tidak setuju sebanyak (4\%), tidak setuju sebanyak (30\%), netral sebanyak (44\%), setuju sebanyak (16\%), dan sangat setuju sebanyak $(6 \%)$.

Pada pertanyaan keempat pada variabel kepemimpinan $\left(\mathrm{X}_{3}\right.$ : Tipe pemimpin partisan) yaitu, "Atasan saya selalu ada disetiap karyawan memiliki masalah" didapatkan hasil sebagai berikut:

Tabel 14

Variabel kepemimpinan $\left(X_{3}\right)$, pertanyaan no. 4

\begin{tabular}{|l|l|l|l|l|l|l|}
\hline Penilaian & STS & TS & N & S & SS & Jumlah \\
\hline Bobot & 1 & 2 & 3 & 4 & 5 & \\
\hline Frekuensi & 2 & 5 & 17 & 18 & 8 & 50 \\
\hline Persentase & $4 \%$ & $10 \%$ & $34 \%$ & $36 \%$ & $16 \%$ & $100 \%$ \\
\hline Nilai & 2 & 10 & 51 & 72 & 40 & \\
\hline
\end{tabular}

Sumber: Data diperoleh dari kuisioner

Pada Tabel 14 variabel kepemimpinan ( $\mathrm{X}_{3}$ : tipe pemimpin partisan ) diatas dapat terlihat responden yang menyatakan sangat tidak setuju sebanyak (4\%), tidak setuju sebanyak (10\%), netral sebanyak (34\%), setuju sebanyak (36\%), dan sangat setuju sebanyak (16\%).

Pada pertanyaan kelima pada variabel kepemimpinan $\left(\mathrm{X}_{3}\right.$ : Tipe pemimpin partisan) yaitu, "Atasan saya mempercayai setiap karyawan demi kepentingan bersama" didapatkan hasil sebagai berikut:

Tabel 15

Variabel kepemimpinan $\left(X_{3}\right)$, pertanyaan no. 5

\begin{tabular}{|l|l|l|l|l|l|l|}
\hline Penilaian & STS & TS & N & S & SS & Jumlah \\
\hline Bobot & 1 & 2 & 3 & 4 & 5 & \\
\hline Frekuensi & 2 & 4 & 18 & 19 & 7 & 50 \\
\hline Persentase & $4 \%$ & $8 \%$ & $36 \%$ & $38 \%$ & $14 \%$ & $100 \%$ \\
\hline Nilai & 2 & 8 & 54 & 76 & 35 & \\
\hline
\end{tabular}

Sumber : Data diperoleh dari kuisioner 
Pada Tabel 15 variabel kepemimpinan $\left(\mathrm{X}_{3}\right.$ : tipe pemimpin partisan ) diatas dapat terlihat responden yang menyatakan sangat tidak setuju sebanyak (4\%), tidak setuju sebanyak (8\%), netral sebanyak (36\%), setuju sebanyak (38\%), dan sangat setuju sebanyak (14\%).

Pada pertanyaan pertama pada variabel kepuasan kerja (Y) yaitu, "Pekerjaan saya cukup menarik sehingga saya tidak bosan" didapatkan hasil sebagai berikut :

Tabel 16

Variabel kepuasan kerja (Y), pertanyaan no. 1

\begin{tabular}{|l|l|l|l|l|l|l|}
\hline Penilaian & STS & TS & N & S & SS & Jumlah \\
\hline Bobot & 1 & 2 & 3 & 4 & 5 & \\
\hline Frekuensi & 0 & 5 & 14 & 21 & 10 & 50 \\
\hline Persentase & $0 \%$ & $10 \%$ & $28 \%$ & $42 \%$ & $20 \%$ & $100 \%$ \\
\hline Nilai & 0 & 10 & 42 & 84 & 50 & \\
\hline
\end{tabular}

Sumber: Data diperoleh dari kuisioner

Pada Tabel 16 variabel kepuasan kerja (Y) diatas dapat terlihat responden yang menyatakan sangat tidak setuju sebanyak (0\%), tidak setuju sebanyak (10\%), netral sebanyak (28\%), setuju sebanyak (42\%), dan sangat setuju sebanyak (20\%).

Pada pertanyaan kedua pada variabel kepuasan kerja (Y) yaitu, "Dibandingkan saya, teman-teman kantor tampak antusias terhadap kerjaan mereka" didapatkan hasil sebagai berikut:

Tabel 17

Variabel kepuasan kerja (Y), pertanyaan no. 2

\begin{tabular}{|l|l|l|l|l|l|l|}
\hline Penilaian & STS & TS & N & S & SS & Jumlah \\
\hline Bobot & 1 & 2 & 3 & 4 & 5 & \\
\hline Frekuensi & 2 & 15 & 25 & 6 & 2 & 50 \\
\hline Persentase & $4 \%$ & $30 \%$ & $50 \%$ & $12 \%$ & $4 \%$ & $100 \%$ \\
\hline Nilai & 2 & 30 & 75 & 24 & 10 & \\
\hline
\end{tabular}

Sumber : Data diperoleh dari kuisioner

Pada Tabel 17 variabel kepuasan kerja (Y) diatas dapat terlihat responden yang menyatakan sangat tidak setuju sebanyak (4\%), tidak setuju sebanyak (30\%), netral sebanyak (50\%), setuju sebanyak (12\%), dan sangat setuju sebanyak (4\%).

Pada pertanyaan ketiga pada variabel kepuasan kerja (Y) yaitu, "Saya pikir pekerjaan saya kurang nyaman" didapatkan hasil sebagai berikut: 


\section{Tabel 18}

Variabel kepuasan kerja (Y), pertanyaan no. 3

\begin{tabular}{|l|l|l|l|l|l|l|}
\hline Penilaian & STS & TS & N & S & SS & Jumlah \\
\hline Bobot & 1 & 2 & 3 & 4 & 5 & \\
\hline Frekuensi & 2 & 18 & 22 & 6 & 2 & 50 \\
\hline Persentase & $4 \%$ & $36 \%$ & $44 \%$ & $12 \%$ & $4 \%$ & $100 \%$ \\
\hline Nilai & 2 & 36 & 66 & 24 & 10 & \\
\hline
\end{tabular}

Sumber : Data diperoleh dari kuisioner

Pada Tabel 18 variabel kepuasan kerja (Y) diatas dapat terlihat responden yang menyatakan sangat tidak setuju sebanyak (4\%), tidak setuju sebanyak (36\%), netral sebanyak (44\%), setuju sebanyak (12\%), dan sangat setuju sebanyak (4\%).

Pada pertanyaan keempat pada variabel kepuasan kerja (Y) yaitu, "Saya sering bosan terhadap pekerjaan saya" didapatkan hasil sebagai berikut :

Tabel 19

Variabel kepuasan kerja (Y), pertanyaan no. 4

\begin{tabular}{|l|l|l|l|l|l|l|}
\hline Penilaian & STS & TS & N & S & SS & Jumlah \\
\hline Bobot & 1 & 2 & 3 & 4 & 5 & \\
\hline Frekuensi & 5 & 15 & 18 & 10 & 2 & 50 \\
\hline Persentase & $10 \%$ & $30 \%$ & $36 \%$ & $20 \%$ & $4 \%$ & $100 \%$ \\
\hline Nilai & 5 & 30 & 54 & 40 & 10 & \\
\hline
\end{tabular}

Sumber : Data diperoleh dari kuisioner

Pada Tabel 19 variabel kepuasan kerja (Y) diatas dapat terlihat responden yang menyatakan sangat tidak setuju sebanyak (10\%), tidak setuju sebanyak (30\%), netral sebanyak (36\%), setuju sebanyak (20\%), dan sangat setuju sebanyak (4\%).

Pada pertanyaan kelima pada variabel kepuasan kerja (Y) yaitu, "Sering kali, saya harus memaksakan diri untuk mau bekerja" didapatkan hasil sebagai berikut:

Tabel 20

Variabel kepuasan kerja (Y), pertanyaan no. 5

\begin{tabular}{|l|l|l|l|l|l|l|}
\hline Penilaian & STS & TS & N & S & SS & Jumlah \\
\hline Bobot & 1 & 2 & 3 & 4 & 5 & \\
\hline Frekuensi & 9 & 14 & 15 & 9 & 3 & 50 \\
\hline Persentase & $18 \%$ & $28 \%$ & $30 \%$ & $18 \%$ & $6 \%$ & $100 \%$ \\
\hline Nilai & 9 & 28 & 45 & 36 & 15 & \\
\hline
\end{tabular}

Sumber : Data diperoleh dari kuisioner

Pada Tabel 20 variabel kepuasan kerja (Y) diatas dapat terlihat responden yang menyatakan sangat tidak setuju sebanyak (18\%), tidak setuju sebanyak (28\%), netral sebanyak (30\%), setuju sebanyak (18\%), dan sangat setuju sebanyak (6\%). 


\section{Hasil dan Pembahasan}

\section{Uji Validitas}

Validitas adalah tingkat keandalah dan kesahihan alat ukur yang digunakan. Instrumen dikatakan valid berarti menunjukkan alat ukur yang dipergunakan untuk mendapatkan data itu valid atau dapat digunakan untuk mengukur apa yang seharusnya di ukur (Sugiyono, 2004:137). Suatu kuesioner dikatakan valid jika item-item pada kuisioner mampu untuk mengungkapkan yang akan diukur oleh kuesioner tersebut. Dengan program SPSS, maka hasil valid ditentukan dengan membandingkan nilai $\mathrm{r}$ dengan kolom Corrected Item Total Correlation. Corrected Item Total Correlation > r tabel maka item-item pernyataan dianggap valid.

Dalam penelitian ini, jumlah sampel (n) adalah 50, maka besarnya $\mathrm{df}=\mathrm{n}-2$ atau $50-2=$ 48 dan alpha $=0,05$ sehingga diketahui $\mathrm{r}$ tabel $=0,2787$ (dengan melihat $\mathrm{r}$ tabel dengan uji dua sisi). Jika nilai r hitung (Corrected Item Total Correlation) > r tabel dan bernilai positif, maka butir pernyataan atau indikator tersebut dinyatakan valid.

\section{Uji Reliabilitas}

Uji Reliabilitas merupakan alat yang digunakan untuk mengetahui ketepatan jawaban kuesioner pada periode yang berbeda. Menurut Sugiyono (2008) instrumen yang reliabel adalah instrumen yang bila digunakan beberapa kali untuk mengukur objek yang sama akan menghasilkan data yang sama. Pengujian statistik ini dengan menggunakan teknik statistik Cronbach's Alpha . jika nilai Cronbach's Alpha $(\alpha)>0,60$ maka variabel tersebut dikatakan reliabel.

\section{Analisis Regresi Linier Berganda}

Analisis regresi berganda digunakan untuk mengetahui pengaruh variabel tipe pemimpin paternalitas (X1), tipe pemimpin otoriter (X2), dan tipe pemimpin partisan (X3) terhadap variabel kepuasan kerja karyawan (Y).

Hasil perhitungan regresi berganda variabel paternalitas (X1), otoriter (X2) dan partisan (X3) terhadap variabel kepuasan kerja karyawan (Y) didapat hasil sebagai berikut: 


\section{Tabel 21}

\section{Analisis Regresi Linier Berganda}

\begin{tabular}{|c|c|c|c|c|c|c|c|c|}
\hline \multicolumn{9}{|c|}{ Coefficients $^{3}$} \\
\hline & & \multicolumn{2}{|c|}{ Unstandardized Coefficients } & \multirow{2}{*}{$\begin{array}{c}\text { Standardiged } \\
\text { Coefficients }\end{array}$} & \multirow[b]{2}{*}{$t$} & \multirow[b]{2}{*}{ Sig. } & \multicolumn{2}{|c|}{ Collinearity Statistics } \\
\hline \multicolumn{2}{|c|}{ Model } & B & Std. Error & & & & Tolerance & VIF \\
\hline \multirow[t]{4}{*}{1} & (Constant) & 2.493 & .508 & & 4.908 & .000 & & \\
\hline & XIRATA &., 191 & .132 & -.260 & -1.449 & .154 & .596 & 1.679 \\
\hline & X2RATA & .181 & 101 & .255 & 1.785 & .081 & .944 & 1.059 \\
\hline & X3RATA & .161 & .186 & 159 & .868 & .390 & .571 & 1,752 \\
\hline
\end{tabular}

Sumber: Hasil Pengolahan SPSS 19

Rangkuman Hasil Analisis Regresi Linier Berganda

$$
Y=2,493-0,191 X_{1}+0,181 X_{2}+0,161 X_{3}
$$

Hasil dari analisis tersebut dapat diinterpretasikan sebagai berikut :

a. Konstanta sebesar $\mathbf{2 , 4 9 3}$ menunjukan bahwa apabila Tipe pemimpin paternalitas (X1), Tipe pemimpin Otoriter (X2), Tipe pemimpin Partisan (X3) dianggap tetap maka diperkirakan Kepuasan kerja Karyawan (Y) akan naik sebesar $\mathbf{2 , 4 9 3}$.

b. Koefisien regresi Tipe pemimpin Paternalitas (X1), sebesar $\mathbf{- 0 , 1 9 1}$ artinya, pemimpin paternalitas meningkat satu satuan maka Kepuasan kerja Karyawan (Y) akan mengalami kenaikan sebesar -0,191 dengan asumsi variabel lain bernilai tetap.

c. Koefisien regresi Tipe pemimpin Otoriter (X2), sebesar 0,181 artinya, pemimpin otoriter meningkat satu satuan maka Kepuasan kerja karyawan (Y) akan mengalami kenaikan sebesar 0,181 dengan asumsi variabel lain bernilai tetap.

d. Koefisien regresi Tipe pemimpin Partisan (X3), sebesar 0,161 artinya, pemimpin partisan meningkat satu satuan maka Kepuasan kerja karyawan (Y) akan mengalami kenaikan sebesar 0,161 dengan asumsi variabel lain bernilai tetap.

Berdasarkan kesimpulan diatas tipe pemimpin paternalitas mempunyai hubungan yang negative dengan kepuasan kerja karyawan. Sedangkan, tipe pemimpin otoriter, tipe partisan mempunyai hubungan yang positif dengan kepuasan kerja karyawan. Hubungan positif ini menunjukkan bahwa tipe pemimpin otoriter, tipe pemimpin partisan. Hubungan negative menunjukkan 
bahwa tipe pemimpin paternalitas berubah berlawanan arah dengan perubahan kepuasan kerja karyawan.

\section{Analisis Korelasi Ganda (R)}

Tabel 22

Pedoman Untuk Memberikan Interpretasi Koefisien Korelasi

\begin{tabular}{|l|l|}
\hline Interval Koefisien & Tingkat Hubungan \\
\hline $0,00-0,199$ & Sangat Rendah \\
$0,20-0,399$ & Rendah \\
$0,40-0,599$ & Sedang \\
$0,60-0,799$ & Kuat \\
$0,80-1,00$ & Sangat Kuat \\
\hline
\end{tabular}

Sumber: Sugiyono, 2008

Dari hasil analisis regresi, pada output model summary ${ }^{b}$ adalah sebagai berikut:

Tabel 23

\section{Hasil Analisis Korelasi Ganda}

\begin{tabular}{|l|l|r|c|c|r|}
\hline Model Summary \\
\hline 1 & $R$ & R Square & $\begin{array}{c}\text { Adjusted R } \\
\text { Square }\end{array}$ & $\begin{array}{c}\text { Std. Error of } \\
\text { the Estimate }\end{array}$ & $\begin{array}{c}\text { Durbin- } \\
\text { Watson }\end{array}$ \\
\hline & $342^{2}$ & .117 & .059 & .48602 & 2.338 \\
\hline
\end{tabular}
a. Predictors: (Constant, X3RATA X2RATA X1RATA
b. Dependent Variable: YRATA

Sumber: Hasil Pengolahan SPSS 19

Berdasarkan Tabel 23 di atas diperoleh hasil $\mathrm{R}$ sebesar 0,342. Hal ini menunjukan bahwa terjadi hubungan yang rendah antara Tipe pemimpin paternalitas, Otoriter dan partisan terhadap Kepuasan kerja karyawan.

\section{Uji Determinan $\left(\mathbf{R}^{2}\right)$}

Koefisien Determinansi $\left(\mathrm{R}^{2}\right)$ pada intinya untuk mengukur proporsi atau persentase sumbangan variabel bebas yaitu variabel tipe pemimpin paternalitas (X1), tipe pemimpin otoriter (X2), tipe pemimpin partisan ( X3) terhadap Kepuasan kerja karyawan (Y) secara bersama-sama, dimana :

$$
\mathbf{0} \leq \mathbf{R}^{2} \leq 1
$$

Jika $\mathrm{R}^{2}$ semakin mendekati 1, maka dapat dikatakan bahwa pengaruh variabel bebas $\left(\mathrm{X}_{1}, \mathrm{X}_{2}, \mathrm{X}_{3}\right)$ terhadap Kepuasan kerja karyawan $(\mathrm{Y})$ adalah besar. Hal ini berarti pertanyaan yang digunakan semakin kuat untuk menerangkan pengaruh variabel bebas $\left(\mathrm{X}_{1}, \mathrm{X}_{2}, \mathrm{X}_{3}\right)$ terhadap Kepuasan kerja karyawan (Y). 
Sebaliknya jika $\mathrm{R}^{2}$ semakin mendekati 0, maka dapat dikatakan bahwa pegaruh variabel bebas $\left(\mathrm{X}_{1}, \mathrm{X}_{2}, \mathrm{X}_{3}\right)$ terhadap Kepuasan kerja karyawan (Y) semakin kecil, hal ini berarti pertanyaan yang digunakan tidak kuat untuk menerangkan pengaruh variabel bebas $\left(\mathrm{X}_{1}, \mathrm{X}_{2}, \mathrm{X}_{3}\right)$ terhadap Kepuasan kerja karyawan $(\mathrm{Y})$.

Tabel 24

\section{Hasil Uji Determinan}

\begin{tabular}{|c|c|c|c|c|c|}
\hline \multicolumn{6}{|c|}{ Model Summary } \\
\hline Model & $R$ & R Square & $\begin{array}{l}\text { Adjusted R } \\
\text { Square }\end{array}$ & $\begin{array}{l}\text { Std. Error of } \\
\text { the Estimate }\end{array}$ & $\begin{array}{l}\text { Durbin- } \\
\text { Watson } \\
\end{array}$ \\
\hline 1 & $342^{3}$ & .117 & .059 & 48602 & 2.338 \\
\hline
\end{tabular}

Sumber: Hasil Pengolahan SPSS 19

Dari tabel di atas dapat dilihat bahwa nilai Adjusted $R$ Square adalah 0,059 Adjusted $R$ Square disebut juga dengan koefisien determinasi sehingga dalam hal ini berarti 59\% menunjukan bahwa persentase sumbangan pengaruh variabel independen (tipe pemimpin paternalitas, otoriter, dan partisan terhadap variabel dependen (Kepuasan kerja karyawan) sebesar 59\%. Sedangkan sisanya sebesar $41 \%$ dipengaruhi atau dijelaskan oleh variabel lain yang tidak dimasukkan dalam penelitian ini.

\section{Uji Asumsi Klasik}

\section{a) Uji Multikolinear}

Gejala multikolinearitas dapat dilihat dari besarnya nilai Tolerance dan VIF. Tolerance mengukur variabilitas variabel terpilih yang tidak dijelaskan oleh variabel independen lainnya. Nilai umum yang biasa dipakai adalah nilai Tolerance $>1$ atau nilai VIF $>10$, maka terjadi gejala multikolinearitas. Sebaliknya jika nilai Tolerance $<1$ atau nilai VIF $<10$, maka tidak terjadi gejala multikolinearitas.

Tabel 25

Hasil Uji Multikolinearitas

\begin{tabular}{|l|l|l|l|}
\hline \multirow{2}{*}{ Variabel } & \multicolumn{2}{|l|}{ Collinearity Statistics } & \multirow{2}{*}{ Keterangan } \\
\cline { 2 - 3 } & Tolerance & VIF & Tidak \\
\hline $\begin{array}{l}\text { Tipe pemimpin } \\
\text { paternalitas }\end{array}$ & .596 & 1.679 & \begin{tabular}{l} 
Multikolinear \\
\hline $\begin{array}{l}\text { Tipe pemimpin } \\
\text { otoriter }\end{array}$
\end{tabular} \\
\hline $\begin{array}{l}\text { Tipe pemimpin } \\
\text { partisan }\end{array}$ & .574 & 1.059 & $\begin{array}{l}\text { Tidak } \\
\text { Multikolinear }\end{array}$ \\
\hline
\end{tabular}

Sumber : Hasil Pengolahan SPSS 19 
Tabel menunjukan hasil analisis uji multikolinearitas. Dari hasil diatas dapat dilihat bahwa VIF $<10$, maka tidak terjadi gejala multikolinearitas dan Tolerance $<1$ maka tidak terjadi gejala multikolinearitas. Jadi dapat disimpulkan bahwa tidak ada multikolinearitas antara variabel bebas dalam model regresi tersebut.

\section{b) Uji Autokorelasi}

Untuk mendeteksi ada tidaknya autokorelasi, melalui tabel Durbin-Watson yang dapat dilakukan dengan program SPSS, dimana secara umum dapat diambil patokan yaitu:

- Jika angka DW < 2,2 berarti tidak terjadi autokorelasi.

- Jika angka DW > 2,2, berarti terjadi autokorelasi.

Untuk hasil uji autokorelasi dalam penelitian ini dapat dilihat pada tabel berikut :

\section{Tabel 26}

\section{Hasil Uji Autokorelasi}

\begin{tabular}{|c|c|c|c|c|c|}
\hline \multicolumn{6}{|c|}{ Model Summary } \\
\hline Model & $R$ & R Square & $\begin{array}{c}\text { Adjusted R } \\
\text { Square }\end{array}$ & $\begin{array}{l}\text { Std. Error of } \\
\text { the Estimate }\end{array}$ & $\begin{array}{l}\text { Durbin- } \\
\text { Watson }\end{array}$ \\
\hline 1 & $342^{3}$ & .117 & .059 & 48602 & 2.338 \\
\hline
\end{tabular}

Sumber : Hasil Pengolahan SPSS 19

Tabel 26 di atas menunjukan nilai DW sebesar 2.338. Karena nilai tersebut berada di atas 2,2 maka menunjukkan adanya gejala autokorelasi pada model regresi ini.

\section{Uji Hipotesis}

\section{a) Uji Simultan (Uji F)}

Untuk mengetahui apakah variable independent yang terdiri dari Tipe pemimpin paternalitas (X1), Otoriter (X2) dan Partisan (X3) secara bersama-sama berpengaruh atau tidak berpengaruh terhadap Kepuasan kerja karyawan (Y), maka harus diuji signifikansinya dengan menggunakan Uji F dengan tingkat signifikansi 0,05.

Tabel 27

\section{Hasil Uji F}

\begin{tabular}{|c|c|c|c|c|c|c|}
\hline \multicolumn{7}{|c|}{ ANONA ${ }^{\mathrm{b}}$} \\
\hline & & $\begin{array}{l}\text { Sum of } \\
\text { Squares }\end{array}$ & df & Mean Square & $F$ & Sig. \\
\hline \multirow{3}{*}{$\frac{M C}{1}$} & Regression & 1.435 & 3 & .478 & 2.025 & $.123^{2}$ \\
\hline & Residual & 10.866 & 46 & .236 & & \\
\hline & Total & 12.301 & 49 & & & \\
\hline
\end{tabular}

Sumber : Hasil Pengolahan SPSS 19 
Hipotesis :

$\mathrm{H}_{0}$

Adanya pengaruh gaya kepemimpinan terhadap kepuasan kerja

karyawan.

$\mathrm{Ha}$

Tidak adanya pengaruh gaya kepemimpinan terhadap kepuasan

kerja karyawan.

Dari hasil uji Anova diatas angka sig sebesar 0,123, pengambilan keputusan juga dapat dilakukan dengan melihat probabilitasnya dimana nilai sig $0.000<0.05$ sehingga $\mathrm{H}_{0}$ ditolak dan $\mathrm{H}_{\mathrm{a}}$ diterima. Artinya Variabel Pengaruh tipe pemimpin paternalitas (X1), otoriter (X2) dan partisan (X3) secara bersama-sama berpengaruh terhadap variabel dependen Kepuasan kerja karyawan.

\section{b) Uji Parsial (Uji t)}

Untuk mengetahui apakah tipe kepemimpinan berupa paternalitas (X1), otoriter (X2) dan partisan (X3) secara parsial berpengaruh signifikan atau tidak terhadap kepuasan kerja karyawan (Y), maka harus diuji signifikansinya dengan menggunakan uji t dengan tingkat signifikansi 0,05 .

Tabel 28

\section{Hasil Uji t}

\begin{tabular}{|c|c|c|c|c|c|c|c|c|}
\hline \multicolumn{9}{|c|}{ Coefficients $^{3}$} \\
\hline \multirow[b]{2}{*}{ Mode } & & \multicolumn{2}{|c|}{ Unstandardized Coefficients } & \multirow{2}{*}{$\begin{array}{c}\begin{array}{c}\text { Standardced } \\
\text { Coefficients }\end{array} \\
\text { Beta }\end{array}$} & \multirow[b]{2}{*}{$t$} & \multirow[b]{2}{*}{ Sig. } & \multicolumn{2}{|c|}{ Collinearity Statistics } \\
\hline & & B & Std. Error & & & & Tolerance & VF \\
\hline \multirow[t]{4}{*}{1} & (Constant) & 2.493 & .508 & & 4.908 & .000 & & \\
\hline & XIRATA & $\cdot 191$ & .132 & $\cdot 260$ & $-1,449$ & .154 & .596 & 1.679 \\
\hline & X2RATA & .181 &, 101 & .255 & 1,785 & .081 & .944 & 1.059 \\
\hline & X3RATA & .161 & .186 & .159 & .868 & 390 & .571 & 1.752 \\
\hline
\end{tabular}

Sumber: Hasil Pengolahan SPSS 19

Berdasarkan Tabel 28 tersebut dapat diketahui hasil uji signifikan secara parsial koefisien regresi variabel tipe pemimpin paternalitas, otoriter dan partisan tidak berpengaruh terhadap kinerja karyawan. Untuk lebih jelasnya dapat dilihat per variabel sebagai berikut :

Ketentuan Uji T dilihat probabilitas Sig dimana jika probabilitasnya lebih kecil dari 0.05 maka $\mathrm{H}_{0}$ ditolak sedangkan jika probabilitasnya lebih besar dari 0.05 maka $\mathrm{H}_{0}$ diterima.

Uji Hipotesis pengaruh tipe kepemimpinan paternalitas terhadap kepuasan kerja karyawan

Dari hasil perhitungan Tabel 4.9.2 kinerja karyawan dapat dilakukan dengan melihat probabilitasnya dimana nilai $-1.449<0.05$ sehingga $\mathrm{H}_{0}$ ditolak maka pengaruh tipe pemimpin paternalitas secara statistik berpengaruh secara parsial terhadap kepuasan kerja karyawan. 


\section{Uji Hipotesis Pengaruh tipe kepemimpinan otoriter terhadap kepuasan kerja karyawan}

Dari hasil perhitungan Tabel 4.9.2 kinerja karyawan dapat dilakukan dengan melihat probabilitasnya dimana nilai $1,785>0.05$ sehingga $\mathrm{H}_{0}$ diterima maka pengaruh tipe kepemimpinan otoriter secara statistik tidak berpengaruh secara parsial terhadap kepuasan kerja karyawan

\section{Uji Hipotesis Pengaruh tipe kepemimpinan partisan Terhadap Kepuasan kerja karyawan}

Dari hasil perhitungan Tabel 4.9.2 kinerja karyawan dapat dilakukan dengan melihat probabilitasnya dimana nilai $0,868>0.05$ sehingga $\mathrm{H}_{0}$ diterima maka pengaruh tipe kepemimpinan partisan secara statistik tidak berpengaruh secara parsial terhadap kepuasan kerja karyawan.

\section{KESIMPULAN}

Berdasarkan hasil penelitian dan pembahasannya mengenai pengaruh motivasi terhadap kinerja karyawan PT. Lion Mentari Airlines, maka dalam bab ini peneliti akan mengambil kesimpulan sebagai berikut:

1. Analisis pengaruh motivasi terhadap kinerja karyawan PT. Lion Mentari Airlines

a) Berdasarkan hasil persamaan regresi menunjukkan bahwa prediksi pengaruh gaya kepemimpinan terhadap kepuasan kerja karyawan bersifat positif. Artinya kepemimpinan berpengaruh baik terhadap kepuasan kerja karyawan PT. Lion Mentari Airlines.

b) Berdasarkan kriteria interpretasi koefisien determinasi menunjukkan, bahwa terdapat pengaruh gaya kepemimpinan terhadap kepuasan kerja karyawan, akan tetapi terdapat pengaruh yang kecil. Sedangkan faktor lain yang tidak terdefinisi, cukup besar mempengaruhi variabel kepuasan kerja karyawan PT. Lion Mentari Airlines.

c) Berdasarkan hasil penelitian secara serempak, ada pengaruh yang signifikan antara variabel tipe kepemimpinan berupa ( paternalitas, otoriter dan partisan ) terhadap kepuasan kerja karyawan PT. Lion Mentari Airlines.

d) Berdasarkan hasil penelitian secara parsial, ketiga variabel tipe kepemimpinan berupa (paternalitas, otoriter, dan partisan) tipe pemimpin paternalitas berpengaruh signifikan terhadap kepuasan kerja karyawan, sedangkan tipe 
pemimpin otoriter dan partisan tidak berpengaruh signifikan terhadap kepuasan kerja karyawan PT. Lion Mentari Airlines.

e) Berdasarkan hasil penelitian, dari ketiga variabel independen yang diuji secara individual, tipe kepemimpinan yang paling dominan dalam mempengaruhi kepuasan kerja karyawan adalah tipe pemimpin Otoriter $\left(\mathrm{X}_{2}\right)$ dengan koefisien 0,181, tipe pemimpin Partisan $\left(\mathrm{X}_{3}\right)$ dengan koefisien 0,161 , dan tipe paternalitas $\left(\mathrm{X}_{1}\right)$ dengan koefisien $-0,191$. Variabel tipe pemimpin otoriter dan partisan berpengaruh positif, sedangkan tipe pemimpin paternalitas berpengaruh negatif.

\section{REFERENSI}

Andhara, S. De, Utami, H. N., \& Mayowan, Y. (2015). Pengaruh Senioritas Dan Loyalitas Terhadap Promosi Jabatan ( Studi pada Karyawan Departemen Kebijakan Ekonomi dan Moneter Bank Indonesia Jakarta ) Abstrak. Jurnal Administrasi Bisnis (JAB), 22(1), 19.

Azwar, M. S. (2016). Pengaruh gaya kepemimpinan, komunikasi, dan disiplin kerja terhadap kinerja karyawan. Jurnal Ilmu Dan Riset Manajemen, 5(3), 1-20.

Handoko, T, H. 2010. Manajemen Peronalia dan Sumber Daya Manusia. Edisi 2.

Hamzah, F. M., Musadieq, M. Al, \& Hakam, M. S. (2013). Pengaruh Senioritas dan Loyalitas terhadap promosi (Studi Pada Karyawan PT. Pembangunan Perumahan DVO III Surabaya). Jurnal Administrasi Bisnis (JAB), 6(2), 1-8.

Jain, R., \& Kaur, S. (2014). Impact Of Work Environment On Job Satisfaction. International Journal of Scientific and Research Publications, 4(1), 1-8.

Kusuma, Y. W. (2016). Pengaruh Motivasi Kerja Dan Insentif Terhadap Semangat Kerja Karyawan CV, F.A Management. Jurnal Ilmu Dan Riset Manajemen, 5(2).

Martoyo, Susilo. 2010. Manajemen dan Sumber Daya Manusia. Edisi 2.

Nitisemito, A. (2010). Manajemen Personalia (Edisi Kede). Jakarta: Ghalia Indonesia.

Priyatno, duwi. (2012). Cara Kilat Belajar Analisis Data Dengan SPSS 20. Yogyakarta: CV. Andi Offset.

Robbins, S. P., \& Judge, T. A. (2008). Perilaku Organisasi Edisi 12. Jakarta: Salemba Empat.

Saputra, H., Hendriani, S., \& Amsal, C. (2014). Pengaruh Kompensasi dan Lingkungan Kerja 
Terhadap Semangat Kerja Karyawan pada PT. Bina Sawit Nusantara (BSN) Pekanbaru. JOM FEKON, 1(2), 1-16.

Sari, D. C. (2015). Pengaruh Lingkungan Kerja Dan Senioritas Terhadap Produktivitas Kerja Dosen Di Jurusan Administrasi Niaga Politeknik Negeri Medan. Jurnal Ilmiah Research Sains, 1(3).

Sugiono. (2014). Metode Penelitian Administrasi Dilengkapi Dengan Metode $R \& D$. Bandung: Alfabeta.

Sunyoto, D. (2011). Metodologi Penelitiana Untuk Ekonomi. Yogyakarta: CAPS.

Suwatno, D., \& Priansa, J. (2014). Manajemen SDM Dalam Organisasi Publik Dan Bisnis. Bandung: CV. Alfabeta.

Tulenan, S. (2015). The Effect Of Work Environment And Compensation Toward Employee Performance At The Office Of State Assets And Auction Service Manado. Jurnal EMBA, 3(3), 672-682.

Widani, N. L. S. (2017). Pengaruh Kompensasi Dan Komunikasi Terhadap Semangat Kerja Karyawan Pada Hotel Puri Dajuma Resort. E-Journal Jurusan Pendidikan Ekonomi, $10(2)$.

Yuliyanti, Y., Istiatin, \& Aryati, I. (2017). Pengaruh Insentif, Disiplin Kerja, Dan Komunikasi Terhadap Kinerja Karyawan Bagian Sewing PT. Pelita Tomangmas Karanganyar. Jurnal Akuntansi Dan Pajak, 18(1), 145-157. 